\title{
Two-ventricle repairs in the unbalanced atrioventricular canal defect spectrum with midterm follow-up
}

\author{
John E. Foker, MD, PhD, ${ }^{\mathrm{a}}$ James M. Berry, RDMS, ${ }^{\mathrm{b}}$ Jeffrey M. Vinocur, MD, ${ }^{\mathrm{b}}$ Brian A. Harvey, BA, ${ }^{\mathrm{a}}$ and \\ Lee A. Pyles, $\mathrm{MD}^{\mathrm{b}}$
}

\begin{abstract}
Objectives: Unbalanced atrioventricular (AV) canal defects include a hypoplastic ventricle (HV) and AV valve (HAVV) precluding complete 2-ventricle repairs (2VRs). Catch-up growth would solve this problem and was induced by increasing HAVV flow. The objectives were to assess reliability of HV and HAVV growth and provide 5- to 15-year 2VR follow-up.
\end{abstract}

\begin{abstract}
Methods: From 1990 to 2005, 23 consecutive infants (13 females and 10 males) with echo-diagnosed unbalanced AV canal defects $(\mathrm{n}=20)$ or subsets $(\mathrm{n}=3)$ underwent 2 VRs. HV volumes (18 left and 5 right) and HAVV sizes estimated from biplane echoes and $\mathrm{z}$ values (standard deviation from expected) were determined. Hypoplasia was defined by a $\mathrm{z}$ value of less than -2.0 . Three operative approaches were used: (1) Staged repairs $(n=9)$ had complete AVV repairs with partial atrial septal defect and ventricular septal defect closures, which increased HAVV flow and maintained stability. The septal defects were closed later. (2) An asymmetric valve partition $(\mathrm{n}=8)$ was used to increase HAVV size. (3) For moderate hypoplasia, HAVV flow was increased and ASDs/VSDs were left for stability $(\mathrm{n}=6)$. Follow-up at 5 to 19 years was done locally.
\end{abstract}

Results: Staged repairs began at 20 to 328 days (average, 129 days) and were completed 5 to 145 days later (average, 101 days). Midterm survival was 87\% (20/23) after 1 central nervous system bleed after trial weaning from extracorporeal membrane oxygenation and 2 later deaths from hyperkalemia. Reoperations for AVV regurgitation $(\mathrm{n}=3), \mathrm{AVV}$ stenosis $(\mathrm{n}=1)$, and mitral valve replacement $(\mathrm{n}=1)$ were satisfactory. On follow-up, all hypoplastic structures (HV and HAVV) had grown to normal size. Two patients "doing well" were lost to follow-up. Survivors have satisfactory 2VRs, with 15 of 18 taking no cardiac failure medications.

Conclusions: Reliable HV/HAVV catch-up growth was induced, and all midterm 2VRs were satisfactory. (J Thorac Cardiovasc Surg 2013;146:854-60)

Supplemental material is available online.

At the most difficult end of the atrioventricular canal (AVC) defect spectrum are the unbalanced lesions with significant hypoplasia of 1 ventricle and, often, the corresponding AV valve. Either side may be deficient, but left-sided hypoplasia with right ventricle $(\mathrm{RV})$ dominance is more common. ${ }^{1-6}$ With significant hypoplasia, the unbalanced AVC (UAVC) defects are usually considered unsuitable for an initial

From the Divisions of Cardiothoracic Surgery ${ }^{\mathrm{a}}$ and Pediatric Cardiology, ${ }^{\mathrm{b}}$ the Lillehei Heart Institute, University of Minnesota, Minneapolis, Minn.

Supported, in part, by the Robert and Sharon Kaster Endowment for Pediatric Cardiac Surgical Science.

Disclosures: Authors have nothing to disclose with regard to commercial support.

Read at the 38th Annual Meeting of The Western Thoracic Surgical Association, Maui, Hawaii, June 27-30, 2012.

Received for publication July 13, 2012; revisions received April 12, 2013; accepted for publication May 2, 2013; available ahead of print July 22, 2013.

Address for reprints: John E. Foker, MD, PhD, Division of Cardiothoracic Surgery, University of Minnesota, MMC 207, 420 Delaware St SE, Minneapolis, MN 55455 (E-mail: foker001@umn.edu).

0022-5223/ $\$ 36.00$

Copyright (c) 2013 by The American Association for Thoracic Surgery

http://dx.doi.org/10.1016/j.jtcvs.2013.05.013 complete 2-ventricle repair (2VR) because of the predictable limitation to either the systemic or pulmonary output. The steep increase in operative mortality with increasing right or left imbalance has long been known. ${ }^{1}$

Because of the limitations hypoplasia imposes on function, considerable effort has been devoted to defining the lower limits of an adequate ventricle and $\mathrm{AV}$ valve (AVV) to avoid a risky complete $2 \mathrm{VR} .{ }^{2-10}$ Unfortunately, neither volume estimates nor the relative lengths of the 2 ventricles using catheterization or echo-derived measurements have established a borderline of adequacy. ${ }^{3}$ More recently, analysis of the relative sizes of the mitral and tricuspid valve components has provided an AVV index (AVVI) to judge the imbalance. ${ }^{2,3}$ Despite the logic behind this approach, a relatively wide transition zone remained, which was marked by unsatisfactory surgical results. ${ }^{2,8}$ When clinical judgments were factored in, the transition zone was even wider, adding more uncertainty to complete 2 VRs and presumably favoring a single-ventricle repair (SVR) track. ${ }^{8}$ An SVR, however, is not an equivalent long-term choice to a $2 \mathrm{VR} .{ }^{11}$

The decision to choose an SVR over a 2VR in infancy, moreover, treats a UAVC defect as a fixed problem and ignores the possibility that catch-up growth could correct the imbalance. The evidence that structural hypoplasia is developmental, rather than primarily genetic in origin, 


$$
\begin{aligned}
& \text { Abbreviations and Acronyms } \\
& \mathrm{AV}=\text { atrioventricular } \\
& \mathrm{AVC}=\mathrm{AV} \text { canal } \\
& \mathrm{AVV}=\mathrm{AV} \text { valve } \\
& \mathrm{AVVI}=\mathrm{AVV} \text { index } \\
& \text { HAVV = hypoplastic AV valve } \\
& \mathrm{HV}=\text { hypoplastic ventricle } \\
& \mathrm{LV}=\text { left ventricle } \\
& \text { MV = mitral valve } \\
& \mathrm{RV}=\text { right ventricle } \\
& \text { SVR = single-ventricle repair } \\
& \mathrm{TV}=\text { tricuspid valve } \\
& \mathrm{UAVC}=\text { unbalanced AVC } \\
& \text { 2VR }=2 \text {-ventricle repair }
\end{aligned}
$$

however, suggests growth should be inducible. ${ }^{12}$ Clinical and basic experimental evidence, moreover, has demonstrated a physiologic ventricular growth signal exists and will tap into an ample growth potential. ${ }^{11}$ We first demonstrated that increased hypoplastic AV valve (HAVV) flow induced catch-up growth of hypoplastic ventricles and valves, allowing a 2VR. ${ }^{11,13}$ This approach, by also allowing intracardiac shunting, will maintain patient stability during growth until the hypoplasia has been corrected and the shunts can be closed.

Although the advantages of a 2VR compared with an SVR seem clear, outside of our series, no reports of this approach to reverse hypoplasia in UAVC patients have appeared. Because this is the first follow-up report on using planned growth to achieve 2VRs in all UAVC patients, several questions were addressed: (1) determine if adequate catch-up growth of ventricular hypoplasia was reliably induced, (2) assess HAVV growth and the quality of the valve repairs, and (3) provide midterm follow-up data on the adequacy and stability of the 2 VRs achieved.

\section{METHODS}

\section{Patient Population}

From 1995-2004, 23 consecutive patients (13 females and 10 males) with a diagnosis of UAVC or a related subset by echocardiography underwent eventual 2VRs. No patient with a diagnosis of UAVC was excluded from this series, and none was placed on an SVR track either initially or secondarily. The initial and follow-up details and course of these patients are presented in Table E1.

\section{Echocardiographic Evaluations}

Both major components of the UAVC defects (hypoplastic ventricles [HVs] and HAVVs) were assessed by echocardiography. The determination of intracardiac and extracardiac anatomy and the ventricular and valve measurements were obtained using a high-resolution echo probe and echocardiography machines from Hewlett-Packard Company (Palo Alto, Calif), Phillips Medical Systems (Irvine, Calif), or Siemens Medical Solutions (Malvern, Pa). Early studies were recorded on videocassettes and later on digital records saved in DICOM format to a picture archiving and communication system.
The preoperative estimation of ventricular volumes and the prediction of postoperative dimensions and function are admittedly difficult because of the complex shapes of the left ventricle (LV) and RV. The most commonly used and accepted LV modeling techniques summarized by Silverman and McElhinney ${ }^{14}$ were used with the acknowledged limitations. Accepted techniques were used for RV analysis. ${ }^{15}$

The volume determinations were obtained from images at end diastole (the frame before onset of AV valve closure), averaged from 3 cardiac cycles. Both 4- and 2-chamber apical and subcostal long axis projections were obtained and provided the biplane area tracings averaged to estimate LV and RV volumes.

The diameters of the mitral valve (MV) and tricuspid valve (TV) components of the common AV valves were determined at the valve hinge points using subcostal short-axis projections to define the relationships of the AVV apparatus to the ventricles and measure diameters. ${ }^{16}$

The ventricular volumes and AVV diameters were indexed to body surface area (meter squared) and compared with normal sizes by calculating the $\mathrm{z}$ values. ${ }^{17}$ The $\mathrm{z}$ values are the SD from the expected size and have been used to assess cardiac structures since the $1990 \mathrm{~s} .{ }^{18}$

\section{Definition of Hypoplasia}

The unbalanced criterion was met by either a ventricle or an $\mathrm{AV}$ valve being hypoplastic, with a $\mathrm{z}$ value $<-2.0$. The $\mathrm{z}$ values between -2.0 to 2.0 are considered to contain $95 \%$ of the normal range. The individual assessment of the HV and HAVVs allowed the spectrum of imbalance to be determined for each structure. Although none of the patients in this series would have generally been considered suitable for a complete $2 \mathrm{VR}$, the significance of the series does not depend on where the line for hypoplasia was drawn. If only patients with hypoplasia of $z<-3.0$ were included, the results and conclusions would be the same, although from a smaller series. At the far end, no patients were turned down, even with severe $(\mathrm{z}=-5.5$ to -7.5) ventricular or AVV hypoplasia.

\section{Volume Determinations and Limitations}

At our institution, the RV and LV end-diastolic volume estimates have used the biplane method from apical 4- and 2-chamber (apical or subcostal) views using the Modified Simpson Rule. Because the ventricular shapes are not symmetrical, the biplane average provides a more accurate volume determination than estimates based on a single-plane, apical, 4-chamber view, which are generally smaller. A biplane study was not always performed on the home follow-up examinations, and in these cases, either a single-plane view or the m-mode LV end-diastolic dimension was used to estimate the volume $\mathrm{z}$ value. The growth responses were robust, however, and even by single-plane echo methods, which gave lower volume estimates; catch-up growth was clearly present.

The variation in size estimates by the different methods of echo analysis also underscores the uncertainty in recommending a $2 \mathrm{VR}$ over an SVR when the choice depends on a preoperative volume, ventricular length ratio, or AVVI estimate. In the growth procedure, moreover, intracardiac shunting maintains stability until sufficient catch-up growth has occurred and the 2 VR can be safely completed.

\section{Surgical Approaches for UAVC Defects}

Although all of these patients were part of the UAVC spectrum, significant structural differences meant not all could be treated the same surgically, and 3 general approaches were used. The surgical details have been presented. ${ }^{11,13}$

Staged repairs $(\mathbf{n}=\mathbf{9})$. The most severe of the UAVC lesions underwent a staged repair designed to produce catch-up growth by increasing flow across the HAVV, with only partial closure of the VSD and ASD. ${ }^{11} \mathrm{~A}$ 2-patch technique was used, and the margins of the patches were placed close to the edge of the septal leaflet of the larger AVV component. ${ }^{11}$ This shifting of the septum increased the HAVV area without compromising the function of the larger $\mathrm{AV}$ valve. 


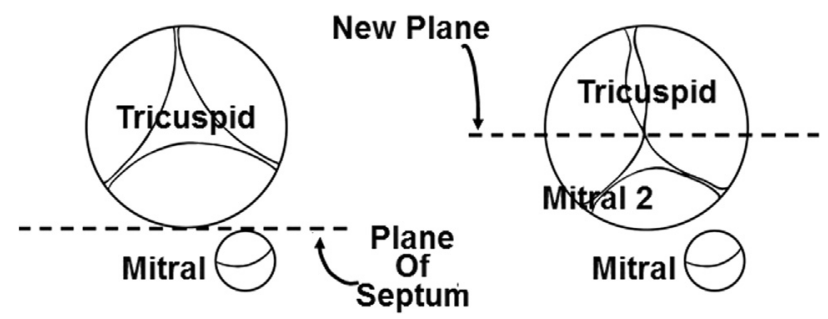

FIGURE 1. Schematic depiction of the creation of a second mitral valve from a large tricuspid valve in an unbalanced atrioventricular (AV) canal defect. On the left, the presence of a small (rudimentary) mitral valve means the large valve is a tricuspid valve, rather than a common $\mathrm{AV}$ valve. The septal plane, therefore, would be as depicted. With a large inlet ventricular septal defect (VSD), however, the ventricular closure patch can be used to shift the septum and create a second mitral valve. On the right, the new septal plane created by the VSD closure patch creates both a second mitral valve (Mitral 2) and leaves an adequate tricuspid valve. The septal line is also used for the atrial septal closure patch. This repair was straightforward.

For RV-dominant UAVC lesions, the RV was kept at systemic pressures by a pulmonary artery band and augmented the systemic output through a planned residual VSD in the ventricular patch. After adequate growth, the VSDs and ASDs were closed and the pulmonary artery band removed.

Within the staged-repair group, there were noteworthy lesions from the far end of the UAVC spectrum. Three patients appeared to have a large common AV valve, but also had a separate, well-formed, but small MV. The large valve, therefore, was a TV positioned over the ventricular septum. The VSD patch was placed to partition the large TV into 2 components, one directed into the $\mathrm{LV}$ producing a second MV to provide adequate LV inflow as the left-sided structures grew and balance was achieved (Figures 1 and E1). ${ }^{19}$ Adequate RV inflow was maintained through the remainder of the TV.

With a left-dominant UAVC, adequate tissue oxygenation was achieved with less than a full cardiac output flowing through the lungs and a VSD was not left open to augment RV output. A mildly restrictive ASD increased TV flow, produced RV growth, and the right to left shunting augmented the cardiac output. For more pulmonary blood flow, a systemic to pulmonary shunt could be placed. The second stage was performed in the catheterization laboratory.

Partitioning to increase the hypoplastic AV valve area $(\mathbf{n}=\mathbf{8})$. When the HAVV was moderately hypoplastic $(\mathrm{z}=-2.1$ to $-5.0)$ and was the predominant abnormality, the atrial and ventricular septal patches were placed close to the edge of the larger component of the common AV valve. This partitioning of the common portion of the AVV increased HAVV area without impairing valve function. ${ }^{11}$

Repair with residual intracardiac shunting $(n=6)$. For less severely unbalanced patients, a restrictive ASD was placed to encourage HAVV flow and induce HV catch-up growth. The planned intracardiac shunting at the atrial level and, in 2 patients, also from small, restrictive VSDs, maintained stability during the growth period and closure could be done in the catheterization laboratory.

\section{Additional Cardiac Operations}

Additional cardiac defects, including tetralogy of Fallot, subaortic membranes, coarctations of the aorta, and a hypoplastic aortic root, were repaired (Table E1).

\section{Patient Follow-up}

The recent status of the patients was assessed by echocardiograms, reports from local cardiologists, clinic visits, and whether cardiac failure medications were required.

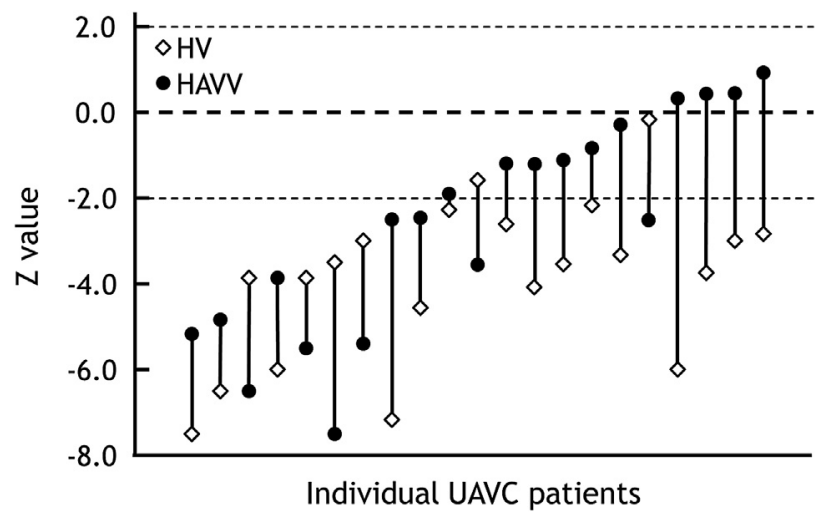

FIGURE 2. Initial ventricular and atrioventricular (AV) valve hypoplasia in individual patients with unbalanced AV canal (UAVC). Vertical bar, an individual patient; open diamond, the $\mathrm{z}$ value of the hypoplastic ventricle $(H V)$; and solid circle, the $\mathrm{z}$ value of the hypoplastic $\mathrm{AV}$ valve $(H A V V)$. These show that there is little uniformity between the degree of hypoplasia in the individual's hypoplastic ventricle and AV valve.

This study was done under Institutional Review Board protocol $1208 \mathrm{E} 19363$.

\section{RESULTS}

All patients tolerated the first operation. Two patients died from hyperkalemia caused by potassium supplements, one outside the hospital awaiting the second stage and the other after completion. One patient, after the second stage, had a central nervous system bleed on ECMO after a satisfactory trial wean, giving a survival of 20/23 (87\%).

\section{Ventricular and AV Valve Growth}

The initial indexed HV volumes and HAVV diameters in individual patients revealed considerable variation in the degree of hypoplasia between these 2 structures. With hypoplasia defined as $\mathrm{z}<-2.0,10$ patients had only a hypoplastic ventricle, whereas 9 had hypoplasia of both ventricle and AVV. For 2 patients, the AVV alone was hypoplastic. Of the 21 patients who had satisfactory biplane evaluations of both the HV and HAVV initially, 20 had a difference of at least $1 \mathrm{z}$ value between them. For 16 patients, the difference was $\mathrm{z} \geq 2$, with the hypoplasia relatively more severe in 11 of the HVs and in 5 of the HAVVs (Figure 2). These variations in the degree of hypoplasia indicate that calculations of imbalance based on either the HV or the HAVV alone will likely not represent all UAVC patients in the group and may not accurately portray the risk of a $2 \mathrm{VR}$.

In patients whose first operations were completed at younger than 1 year, the initial $\mathrm{HV}$ volumes were $4.5 \pm$ $2.1 \mathrm{~mL}(\mathrm{n}=14)$, with a corresponding $\mathrm{z}$ value of $-4.4 \pm$ 1.8. The initial HV volume in patients whose first operations were done at older than 1 year was $14.1 \pm 6.6 \mathrm{~mL}$ $(\mathrm{n}=6)$, with a corresponding $\mathrm{z}$ value of $-3.8 \pm 1.2$. 


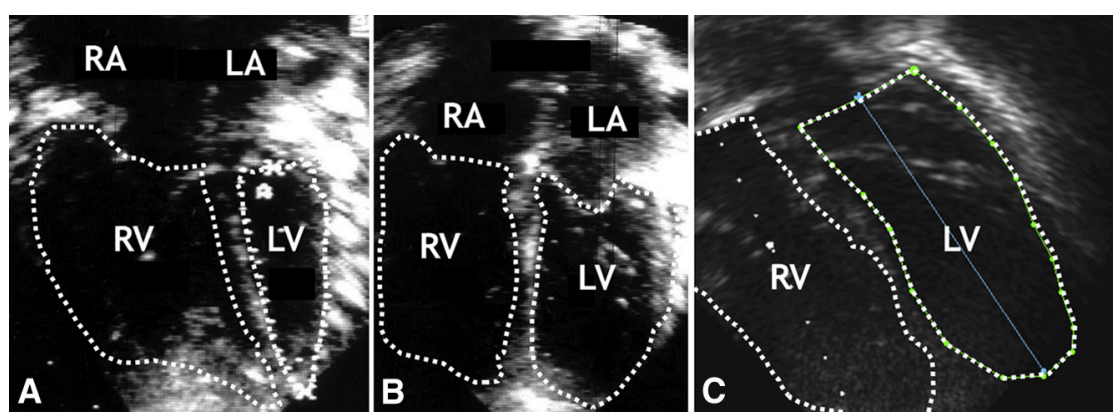

FIGURE 3. Left ventricular growth induction by staged repair shown by sequential echo studies in a patient with unbalanced atrioventricular canal. A, Preoperative study (aged 2 months) shows a non-apex-forming left ventricle ( $L V$ ) with an indexed volume of $4.5 \mathrm{~mL}$ and a $\mathrm{z}$ value of -7.1 . B, After a period of growth induction (aged 5 months) and before the second stage of repair, the $\mathrm{LV}$ volume was $11.6 \mathrm{~mL}$ and the $\mathrm{z}$ value was -2.4 . C, Followup of completed repair (aged 13 years), with an $\mathrm{LV}$ volume of $83 \mathrm{~mL}$ and a z value of -1.9 . $R V$, Right ventricle; $R A$, right atrium; $L A$, left atrium.

The follow-up volumes of the HVs for all patients (11.7 \pm 3.2 years) had an indexed range of $80.4 \pm 31.2 \mathrm{~mL}$ and a corresponding $\mathrm{z}$ value of $-0.7 \pm 1.1$. The 2 patients with volume $\mathrm{z}$ values of -2.5 and -2.8 had single plane-echo determinations that give smaller volume estimates.

The growth response was seen by both individual studies and graphs of the indexed volumes and $\mathrm{z}$ values (Figures 3 and 4). The magnitude was seen by 1 indexed LV volume, which grew from 1.3 to $77 \mathrm{~mL}$, and the rapidity by the severely hypoplastic ventricles, which grew to normal size in 3 to 6 months in staged repairs (Figures 3 and 5).

The initial HAVV diameter in patients whose first operations were completed at younger than 1 year $(156 \pm 109$ days) was $7.5 \pm 2.4 \mathrm{~mm}(\mathrm{n}=9)$, with a corresponding $\mathrm{z}$ value of $-4.2 \pm 1.7$. The initial HAVV diameter in patients with first operations at older than 1 year $(589 \pm 256$ days) was $7.0 \pm 2.1 \mathrm{~mm}(\mathrm{n}=2)$, with a corresponding $\mathrm{z}$ value of $-6.0 \pm 0.8$.

The follow-up HAVV diameters of all patients $(9.8 \pm 2.2$ years) had an indexed range of $22.5 \pm 3.9 \mathrm{~mm}$ and a corresponding $\mathrm{z}$ value of $0.2 \pm 0.7$. In 1 patient with a rudimentary mitral valve, the indexed mitral area grew from 0.27 to $1.9 \mathrm{~cm}^{2} / \mathrm{m}^{2}{ }^{19}$ Plotting the patients who had adequate echo studies showed the growth response of the HAVVs (Figure 6).

All second stages were completed, and the planned intracardiac shunts closed, in several cases spontaneously.

\section{Additional Structural Abnormalities}

A concern has been that the 2VRs may not be satisfactory for the long-term because of associated cardiac abnormalities, principally of the MVs. ${ }^{5}$ Mitral regurgitation after the initial repair occurred in 3 patients with successful reoperation. Of the 3 patients, 1 whose large TV was divided to create a second MV continued to have significant regurgitation because a quadrant of the valve was without chordae. A mechanical valve (St Jude Medical, Inc, St Paul, Minn) was placed and recently upsized. Her cardiac function remains good. The other 2 have shown surprising growth of the rudimentary MVs. ${ }^{19}$

Four patients had an MV parachute deformity that required repair at the initial operation. Three patients have
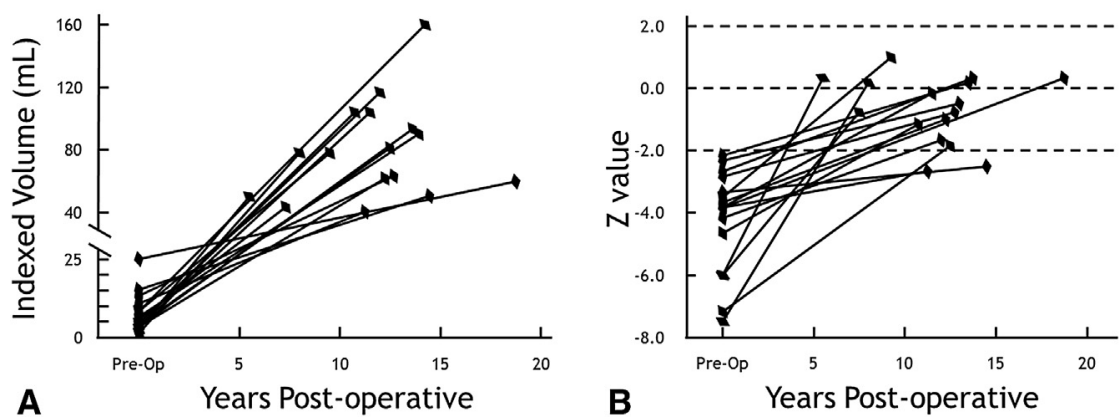

FIGURE 4. Growth in ventricular volumes for 16 patients with unbalanced atrioventricular canal. The initial and midterm follow-up echo studies show that stable ventricular growth has occurred in these patients. (From the 23 patients originally, 3 deaths, 2 lost to follow-up, and 2 who had an inadequate echo study left the 16 patients depicted.) A, Indexed ventricular volumes. Bar, an individual patient, depicting the change from initial (preoperative) to follow-up indexed volumes after growth induction. B, Ventricular volume $\mathrm{z}$ values. Bar, change in the $\mathrm{z}$ values of the ventricular volumes with growth for an individual patient. The 2 patients who did not reach a $\mathrm{z}$ value of -2.0 had only a single-plane follow-up echo study, a technique that results in lower-volume estimates. 


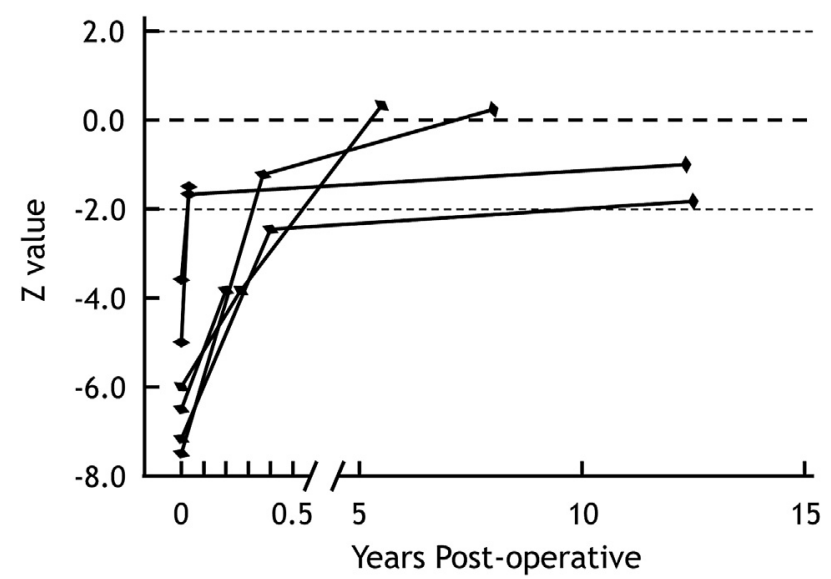

FIGURE 5. Rapid ventricular growth induction by staged repair for 5 patients with unbalanced atrioventricular canal. For patients with more severe hypoplasia, a staged repair was used to induce catch-up growth of these ventricles. Bar, an individual patient tracking the initial and postgrowth induction values; and solid diamonds, volume $\mathrm{z}$ values at those time points. These patients were followed up more closely, with echo studies within 5 months, and usually much sooner after the growth-inducing procedure. These results show that catch-up growth was relatively rapid and the 2-ventricle repair was completed within a few months. The patients depicted were those who had satisfactory serial echo studies available.

required no subsequent operations, but 1 has had 2 additional operations to relieve mitral and LV outflow track obstructions, with sufficient success to avoid an MV replacement. In 2 patients, the MV had 2 layers, with a second smaller septal leaflet lower than the normal leaflet; these were satisfactorily resected.

Right dominant lesions had smaller aortic valves and aortas, but all but one grew satisfactorily with increased flow. Four patients had coarctation of the aorta, and one had a type A interrupted aortic arch repaired in infancy. A small LV outflow track and aortic valve annulus in one patient eventually required a Ross procedure and, recently, an aortic valve replacement. One patient had satisfactory repair of tetralogy of Fallot. Four patients developed a subaortic membrane that was resected, with mild aortic regurgitation persisting in one.

For the series, including the 2 patients with valve replacements, good 2 VRs were found in all but 1 , the patient with the more severe mitral parachute deformity who, nevertheless, remains with good function and activity levels.

\section{Follow-up Evaluations}

The difficulty in accomplishing these evaluations speaks to how well the patients are doing. Of the 20 survivors, 2 have been lost to follow-up, although judged to be "doing well" when last seen. For the remainder, local clinic visits have often been infrequent and there was reluctance, by the insurance providers, for echo studies. Consequently,

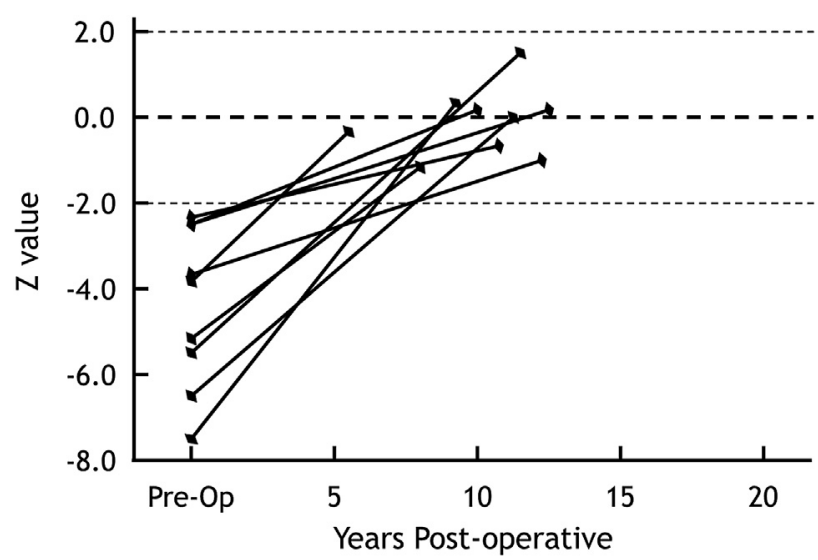

FIGURE 6. Growth in valve area for 9 patients with unbalanced atrioventricular canal. Bar, an individual patient with the initial and follow-up $\mathrm{z}$ values for the size of the hypoplastic AV valves (solid diamonds). The catch-up growth of the hypoplastic AV valves is somewhat slower than for the growth of the ventricles (data not shown), but they reliably reach and maintain a normal size.

some of the follow-up studies were done 2 to 4 years previously.

A good indication of their functional status is that 15 of 18 patients are not taking cardiac failure medications. The patients with valve replacements (1 mitral and 1 aortic) are taking warfarin (Coumadin) but have good function.

\section{DISCUSSION}

The UAVC defects comprise the difficult end of the AVC spectrum and are characterized by significant hypoplasia of either the LV (most common) or RV and usually the corresponding AVV. The UAVC lesions comprise only approximately $10 \%$ of AVC defects, but they contribute disproportionately to the operative mortality. ${ }^{1-9}$

To improve the operative results, considerable effort has been devoted to defining when the degree of hypoplasia precludes an initial, complete 2VR, making an SVR necessary. Methods for judging hypoplasia have included ventricular volumes or length ratios or by determining the AVVIs to predict whether the UAVC patient will tolerate an initial complete 2VR. Despite these efforts, the border has not sharpened and adding the variations in clinical diagnosis further widen the transition zone. ${ }^{8}$

Clearly, an SVR track is not an equivalent choice to a 2VR. At best, it is palliative, with significant difficulties appearing in the medium term. ${ }^{20,21}$ Moreover, a UAVC defect has been identified as a risk factor for a poor outcome for a Fontan procedure. $^{22}$

This study provides information on why the transition zone between 2VRs and SVRs will be difficult to eliminate. We found considerable differences in the degree of hypoplasia between the ventricular and the AVV sizes (Figure 2). Consequently, measurements of either the HVs or HAVVs 
alone will not produce an accurate assessment of the degree of hypoplasia in a group of UAVC patients.

Judging the degree of imbalance has also proved difficult because of difficulties in measuring ventricular size and, to some degree, the area of the AVV components. ${ }^{18}$ Although there is general agreement that normal ventricular and AV valve size falls between the $\mathrm{z}$ values of -2.0 and 2.0 , any conclusion is tempered by the imprecision of methods used to measure the hypoplastic structures and to calculate $\mathrm{z}$ values. Finally, size and functional adequacy are not necessarily the same. When these significant limitations and additional clinical issues are factored in, the possibility of defining a sharp border between an initial 2VR and an SVR track seems unlikely, at best.

The most important finding of this study, however, is that even severe degrees of hypoplasia can be reversed and a 2 VR eventually realized. In addition, during the growth period, stability will be maintained by intracardiac shunting. An initial decision to pursue an SVR based on the degree of hypoplasia, in contrast, fixes the outcome early in infancy and ignores the growth capability of the hypoplastic structures. ${ }^{11}$ As these results demonstrate, however, catchup growth can be induced in these hypoplastic structures and is relatively rapid (Figures 3 and 5). This principle is generally applicable and, in patients with pulmonary atresia with an intact septum, hypoplastic RVs and tricuspid valves with $\mathrm{z}$ values lower than -4.0 grew to normal size. ${ }^{13,23}$ Our experience has also shown that the technical details are important and include a mildly restrictive $(4-5 \mathrm{~mm} \mathrm{Hg}$ ) ASD to increase HAVV flow and stimulate ventricular growth as well as complete relief of outflow obstruction to maximize the response. Finally, even if the growth response is not completely adequate, the initial valve repair will still be beneficial to a ventricle and a half repair.

An additional benefit was that patient stability was improved during the growth period because intracardiac shunting was preserved. In contrast to the "all-or-nothing" complete 2VR, which underlies the unsatisfactory results of patients in the transition zone in other series, these patients were relatively stable. These patients are usually stable before the first operation if pulmonary blood flow is not excessive. The value of this intracardiac shunting has not been well appreciated, although 1 report of left-dominant UAVC patients states it may be useful in "selected cases."10

The midterm results seem favorable for these patients, as their infrequent visits to their cardiologists testify. For the 18 surviving patients who had been seen within the past 4 years, all had 2VRs with the original hypoplasia corrected. Only an incompletely relieved mitral parachute deformity in 1 and an AVR and an MVR in 2 others are continuing issues. Most remarkably, 15 were taking no cardiac failure medications. These patients need little or no cardiac care at a time SVR patients often would be developing significant difficulties.
Some additional points regarding anatomy, repair, and function have emerged from this study. It has been proposed that the AVVI also reveals the degree of AV junction malalignment that may alter inflow physiology and further hamper HV function. ${ }^{8}$ Our results, however, do not support that junctional malalignment affects inflow or function of the $\mathrm{HV}$, nor that the original septal line between the AVV components needs to be preserved. Throughout this series, a 2-patch technique was routinely used to enlarge the HAVV as much as possible by shifting the septum into the larger component. ${ }^{11}$ This technique had the immediate effect of increasing the area of the HAVV and seemed not to affect function of either AVV.

The concern that valve abnormalities, principally mitral, could interfere with the quality of a $2 \mathrm{VR}$, making it less satisfactory than an SVR, has validity. ${ }^{5} \mathrm{MV}$ regurgitation required a second operation in 3 patients and an MVR in a fourth. Despite these difficulties, the quality of life and the relative freedom from continuing cardiac difficulties for most patients in this series argue persuasively for this approach.

In summary, this approach takes advantage of the significant growth potential present in infants and young children. Although this series is relatively small, our results suggest that even severely hypoplastic ventricles and valves are capable of a catch-up growth response. Growth and development is central to the field of pediatrics, and these results show that by enlisting normal physiologic growth signals, severe problems of underdevelopment can be corrected. The result was often an essentially normal cardiac configuration and function whose benefits should increase with time compared with the significant compromises produced from having only 1 ventricle.

\section{References}

1. Studer M, Blackstone EH, Kirklin JW, Pacifico AD, Soto B, Chung GK, et al. Determinants of early and late results of repair of atrioventricular septal (canal) defects. J Thorac Cardiovasc Surg. 1982;84:523-42.

2. Cohen MS, Jacobs ML, Weinberg PM, Rychik J. Morphometric analysis of unbalanced common atrioventricular canal using two-dimensional echocardiography. J Am Coll Cardiol. 1996;28:1017-23.

3. Jegatheeswaran A, Pizarro C, Caldarone CA, Cohen MS, Baffa JM, Gremmels DB, et al. Echocardiographic definition and surgical decision-making in unbalanced atrioventricular septal defect: a congenital heart surgeons' society multiinstitutional study. Circulation. 2010;122(suppl):S209-15.

4. van Son J, Phoon CK, Phil M, Silverman NH, Hass GS. Predicting feasibility of biventricular repair of right-dominated unbalanced atrioventricular canal. Ann Thorac Surg. 1997;63:1657-63.

5. Cohen MS, Spray TL. Surgical management of unbalanced atrioventricular canal defect. Semin Thorac Cardiovasc Surg Pediatr Card Surg Annu. 2005;135:44.

6. Delmo Walter EM, Ewert P, Hetzer R, Hubler M, Alexi-Meskishvili V, Lange P, et al. Biventricular repair in children with complete atrioventricular septal defect and a small left ventricle. Eur J Cardiothorac Surg. 2008;33:40-7.

7. Owens GE, Gomez-Fifer C, Gelehrter S, Owens ST. Outcomes for patients with unbalanced atrioventricular septal defects. Pediatr Cardiol. 2009;30:431-5.

8. Overman DM, Baffa JM, Cohen MS, Meterns L, Gremmels DB, Jegatheeswaram A, et al. Unbalanced atrioventricular septal defect: definition and decision making. World J Pediatr Congen Heart Surg. 2010;1:91-6.

9. Cohen MS, Rychik J. The small left ventricle: how small is too small for biventricular repair? Sem Thor Cardiol Surg Ped Cardiol Surg Ann. 1999;2:189-202. 
10. De Oliveira NC, Sittiwangkul R, McCrindle BW, Dipchand A, Yun TJ, Coles JG, et al. Biventricular repair in children with atrioventricular septal defects and a small right ventricle: anatomic and surgical considerations. J Thorac Cardiovasc Surg. 2005;130:250-7.

11. Foker JE, Berry JM, Steinberger J. Ventricular growth stimulation to achieve twoventricle repair in unbalanced common atrioventricular canal. Prog Ped Cardiol. 1999; 10:173-86.

12. Sedmera D. Factors in ventricular and atrioventricular valve growth: an embryologist's perspective. Prog Ped Cardiol. 2010;29:11-4.

13. Foker JE, Berry J, Setty SP, Harvey BA, Rivard AL, Gittenberger-de Groot AC, et al. Growth and function of hypoplastic right ventricles and tricuspid valves in infants with pulmonary atresia and intact ventricular septum. Prog Ped Cardiol. 2010;29:49-54.

14. Silverman NH, McElhinney DB. Which two ventricles cannot be used for a biventricular repair? echocardiographic assessment. Ann Thorac Surg. 1998;66: 634-40.

15. Gibson TC, Miller SW, Aretz T, Hardin NJ, Weyman AE. Method for estimating right ventricular volume by planes applicable to cross-sectional echocardiography: correlation with angiographic formulas. Am J Cardiol. 1985;55: 1584-8.
16. Minich LA, Snider AR, Bove EL, Lupinetti FM, Vermillion RP. Echocardiographic evaluation of atrioventricular orifice anatomy in children with atrioventricular septal defect. J Am Coll Cardiol. 1992;19:149-53.

17. Daubeney PE, Blackstone EH, Weintraub RG, Slavik Z, Scanlon J, Webber SA Relationship of the dimension of cardiac structures to body size: an echocardiographic study in normal infants and children. Cardiol Young. 1999;9:402-10.

18. Kirklin JW, Barratt-Boyes BG. Anatomy, dimensions, and terminology. In: Kirklin JW, Barratt-Boyes BG, eds. Cardiac Surgery. 2nd ed. New York, NY: Churchill Livingstone; 1993:24-60.

19. Foker JE, Berry JM, Harvey BA, Pyles LA. Mitral and tricuspid valve repair in unbalanced atrial ventricular canal defects. J Thorac Cardiovasc Surg. 2012;143:S29-32.

20. Fontan F, Kirklin JW, Fernandez G, Costa F, Naftel DC, Tritto F, et al. Outcome after a "perfect" Fontan operation. Circulation. 1990;81:1520-36.

21. Rychik J, Goldberg D, Dodds K. Long-term results and consequences of single ventricle palliation. Prog Ped Cardiol. 2010;29:19-24.

22. Stasik CN, Goldberg CS, Bove EL, Devaney EJ, Ohye RG. Current outcomes and risk factors for the Norwood procedure. J Thorac Cardiovasc Surg. 2006;131:412-7.

23. Foker JE, Setty SP, Berry JM, Jain P, Catton K, Gittenberger-de Groot AC, et al. Treatment of right coronary artery connections in infants with pulmonary atresia and intact ventricular septum. J Thorac Cardiovasc Surg. 2008;136:749-56. 


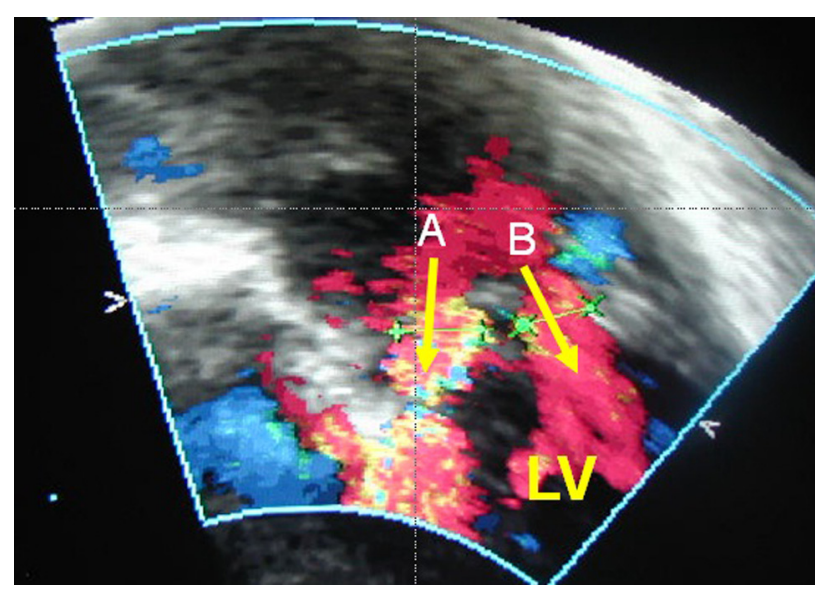

FIGURE E1. Doppler echocardiogram showing inflow through the created mitral valve (mitral 2$)$ into the left ventricle $(L V)$. The red Doppler stream into the LV through the newly created mitral valve $(A)$ appears larger than the stream through the native, but rudimentary, mitral valve (B). Together, they allow a satisfactory output, giving time for the hypoplastic LV to grow. At this point, a small atrial septal defect and a small ventricular septal defect are present, which also increase patient stability. 
TABLE E1. Data on patients with an unbalanced AV canal defect

\begin{tabular}{|c|c|c|c|c|c|c|c|c|c|c|c|c|c|c|c|c|}
\hline \multicolumn{7}{|c|}{ Patient characteristics } & \multicolumn{7}{|c|}{ Before initial operation } & \multicolumn{3}{|c|}{ Before second operation } \\
\hline \multirow[b]{2}{*}{ Patient } & \multirow[b]{2}{*}{ YOB } & \multirow{2}{*}{$\begin{array}{c}\text { Hypo } \\
\text { vent }\end{array}$} & \multirow[b]{2}{*}{ Hypo valve } & \multirow[b]{2}{*}{ PAB } & \multirow{2}{*}{$\begin{array}{c}\text { Additional } \\
\text { cardiac } \\
\text { operations }\end{array}$} & \multirow[b]{2}{*}{ Down } & \multirow[b]{2}{*}{ Date } & \multirow{2}{*}{$\begin{array}{l}\text { Age at } \\
\text { Op, d }\end{array}$} & \multirow[b]{2}{*}{ Wt, kg } & \multicolumn{2}{|c|}{ HAVV } & \multicolumn{2}{|r|}{ HV } & \multirow{2}{*}{\multicolumn{2}{|c|}{$\begin{array}{c}\text { Days } \\
\text { between } \\
\text { Ops } \\
\end{array}$}} & \multirow[b]{2}{*}{ Wt, kg } \\
\hline & & & & & & & & & & $\mathbf{m m}$ & $\mathrm{z}$ value & $\mathbf{m L}$ & $\mathrm{z}$ value & & & \\
\hline \multicolumn{17}{|c|}{ Staged Repair } \\
\hline 1 & 1995 & Left & Mitral & Yes (1995) & $\begin{array}{l}\text { Coarctation } \\
\text { repair }\end{array}$ & No & 1996 & 321 & 6.3 & 10 & -2.5 & 4.5 & -7.1 & 1996 & 141 & 8.2 \\
\hline 2 & 1996 & Left & Mitral & No & $\begin{array}{l}\text { Tetralogy of } \\
\text { Fallot repair }\end{array}$ & No & 1996 & 101 & 4.6 & NA & NA & 1.5 & -5 & 1996 & - & - \\
\hline 3 & 1997 & Left & Mitral & Yes (1997) & $\begin{array}{l}\text { Type A } \\
\text { interrupted } \\
\text { aortic arch }\end{array}$ & No & 1997 & 20 & 3.4 & 10 & -0.8 & 3.6 & -2.1 & 1998 & 145 & $\mathrm{NA} \dagger$ \\
\hline 4 & 1998 & Left & Mitral & $\begin{array}{l}\text { Yes } \\
\text { (previous, } \\
\text { D) }\end{array}$ & No & No & 1998 & 92 & 3.0 & 9 & -1.1 & 3.2 & -3.6 & 1998 & 5 & 3.0 \\
\hline 5 & 1999 & Left & Mitral & No & No & No & 1999 & 59 & 4.1 & 6.5 & -3.6 & 6.5 & -1.6 & 1999 & 108 & 5.0 \\
\hline 6 & 2003 & Left & Mitral & Yes (2003) & $\begin{array}{l}\text { Coarctation } \\
\text { repair }\end{array}$ & No & 2003 & 77 & 5.3 & 5.6 & -5.1 & 1.3 & -7.5 & 2004 & 134 & 7.7 \\
\hline 7 & 2002 & Left & Mitral & No & $\begin{array}{l}\text { Coarctation } \\
\text { repair }\end{array}$ & Yes & 2003 & 328 & 7.9 & 6 & -4.8 & 4.7 & -6.5 & 2003 & 76 & 8.4 \\
\hline 8 & 2004 & Left & Mitral & Yes (2004) & No & No & 2004 & 32 & 4.2 & 6 & -3.9 & 2.7 & -6 & 2004 & 101 & 8.1 \\
\hline 9 & 2003 & Left & Mitral & No & No & Yes & 2003 & 193 & 7.5 & 4 & -7.5 & 8.4 & -3.5 & & & \\
\hline \multicolumn{17}{|c|}{ HAVV partitioning } \\
\hline 10 & 1991 & Left & Mitral & Yes (1992) & No & Yes & 1994 & 770 & 10.6 & 8.5 & -5.4 & 12 & -3 & & & \\
\hline 11 & 1993 & Left & Mitral & Yes (1994) & No & Yes & 1996 & 845 & 12.5 & 16 & -0.3 & 15.6 & -3.3 & & & \\
\hline 12 & 1995 & Left & Mitral & Yes (1995) & No & No & 1997 & 653 & 8.2 & 17 & 0.9 & 12.5 & -2.8 & & & \\
\hline 13 & 1998 & Left & Mitral & No & No & No & 1998 & 99 & 3.8 & 11 & -5.5 & 3.8 & -3.9 & & & \\
\hline 14 & 1998 & Left & Mitral & No & No & No & 1998 & 193 & 5.2 & 9 & -1.9 & 8.3 & -2.2 & & & \\
\hline 15 & 2000 & Left & Mitral & No & No & No & 2000 & 83 & 4.7 & 10 & -1.2 & 4.5 & -4.1 & & & \\
\hline 16 & 2000 & Right & Tricuspid & No & No & No & 2001 & 73 & 4.2 & 13 & 0.4 & 4.5 & -3 & & & \\
\hline 17 & 2000 & Right & Tricuspid & $\begin{array}{l}\text { Yes } \\
\text { (previous, } \\
\text { D) }\end{array}$ & No & Yes & 2001 & 382 & 6.2 & 15 & 0.3 & 6.1 & -6 & & & \\
\hline \multicolumn{17}{|c|}{ Residual intracardiac shunting } \\
\hline 18 & 1990 & Left & Mitral & Yes (1991) & No & Yes & 1999 & 3126 & 21.4 & 20 & 0.4 & 26 & -3.8 & & & \\
\hline 19 & 1998 & Right & Tricuspid & No & No & No & 1998 & 157 & 5.5 & 15 & -1.2 & 6.6 & -2.6 & & & \\
\hline 20 & 1999 & Left & Mitral & No & No & No & 1999 & 108 & 4.5 & 8 & -2.4 & 4.7 & -4.6 & & & \\
\hline 21 & 1999 & Right & Tricuspid & $\begin{array}{l}\text { Yes } \\
\qquad(1999, \mathrm{D})\end{array}$ & No & Yes & 2000 & 408 & 9.7 & 5.5 & -6.5 & 12.5 & -3.9 & & & \\
\hline 22 & 2000 & Left & Mitral & No & Coarctation repair & No & 2000 & 164 & 9.2 & 15 & 0.1 & NA & NA & & & \\
\hline 23 & 2002 & Right & Tricuspid & No & No & No & 2003 & 184 & 7.1 & 10 & -2.5 & 16 & -0.2 & & & \\
\hline
\end{tabular}

The initial, interim, and follow-up data on the 23 patients in this series are presented. YOB, Year of birth; Hypo, hypoplastic; Vent, ventricle; PAB, pulmonary artery band; Down, trisomy 21; $O p$, operation; $W t$, weight; $H A V V$, hypoplastic atrioventricular valve; $H V$, hypoplastic ventricle; $U A V C$, unbalanced atrioventricular canal; SubAo Memb, subaortic membrane; Meds, medications; $N A$, not available; $D$, done elsewhere; $M V$, mitral valve; $C N S$, central nervous system; $F / U$, follow-up; $R V$, right ventricle; $T V$, tricuspid valve. *Died from hyperkalemia outside hospital awaiting second operation. †Echo studies before second operation not available. ‡In addition to aortic regurgitation, has mitral parachute deformity. §Died 16 months after repair from hyperkalemia. $\uparrow$ Died from a central nervous system bleed after second operation, was on extracorporeal membrane oxygenation support for initial marginal output and had a successful trial wean. 
TABLE E1. Continued

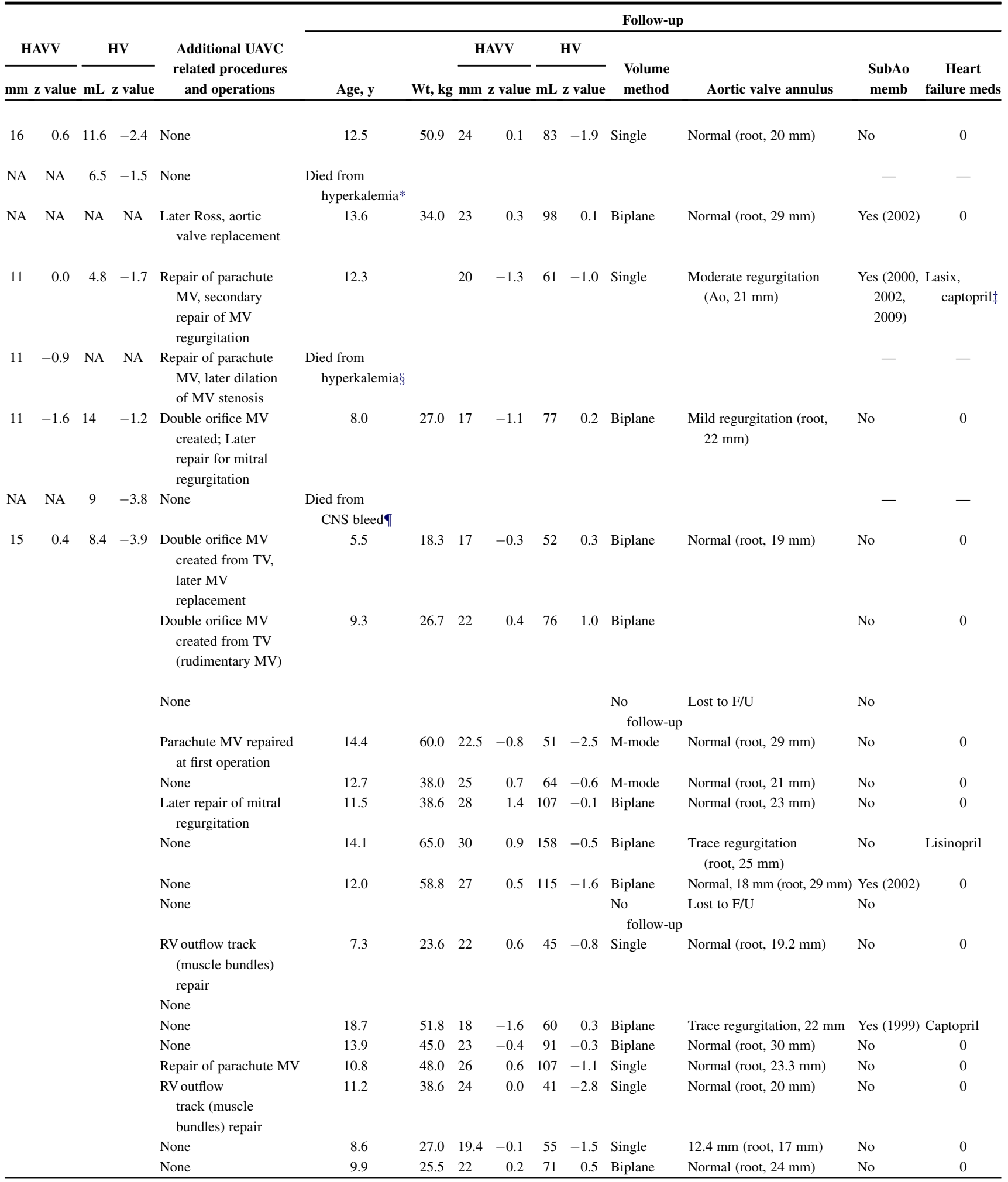

